\title{
Laboratory tests in rigid pavement
}

\author{
Mezgeen A. Rasol \\ RMEE Department \\ EEBE-Universitat Politècnica de \\ Catalunya \\ Barcelona, Spain \\ mezgeen.rasol@upc.edu \\ Sonia Santos-Assunçao \\ AAMAQ Geophysical \& Geological \\ Studies \& Services \\ Dubai, United Arab Emirates \\ soniaassunçao@aamaq.ae
}

\author{
Jorge C. Pais \\ Department of Civil Engineering \\ University of Minho \\ Guimarães, Portugal \\ jpais@civil.uminho.pt \\ Viviana Sossa \\ RMEE Department \\ EEBE-Universitat Politècnica de \\ Catalunya \\ Barcelona, Spain \\ viviana.alejandra.sossa@upc.edu
}

Mercedes Solla

Centro Universitario de la Defensa

Escuela Naval Militar - Universidad de Vigo

Marin, Spain

merchisolla@cud.uvigo.es

Vega Perez-Gracia

RMEE Department

EEBE-Universitat Politècnica de Catalunya

Barcelona, Spain

vega.perez@upc.edu

\begin{abstract}
Deterioration of concrete structure is consequence of aging, applied loads and weathering. In this paper, several laboratory tests were presented, compared to computational models and a field test case study. The purpose of the laboratory measurements is the analysis of the results in the case of different size cracks in concrete beams, filled with several materials.
\end{abstract}

Keywords-GPR, laboratory tests, cracks, concrete beams.

\section{InTRODUCTION (HEADING 1)}

Deterioration of concrete structure is consequence of aging, applied loads and weathering. Cracking is one of the most frequent damage as consequence of tensions during deformation of concrete elements [1, 2, 3]. In many cases, cracks appear in hidden areas, covered by other materials. It is the case of rigid pavements composed by cement concrete layers below a flexible bituminous layer. In those cases, cracks usually propagate, affecting finally to the most superficial layer. Rehabilitation and maintenance of the concrete layer below other materials involved in some cases the application of destructive methods to find the cracks, requiring the removal of large areas of the covering layers.

However, in many cases, non-destructive techniques could be applied in order to define an approach of the damage, reducing dramatically the areas affected by renovations or destructive testing. Several techniques are based in the transmission of mechanical or electromagnetic waves. One of the most widespread technique in civil engineering is Ground Penetrating Radar (GPR) because its ability in detecting small discontinuities such as cracks.

However, GPR images are difficult to interpret, requiring in many cases additional tests or even numerical models. This work presents the laboratory tests designed in order to define the ability of the method in the detection of different groups of cracks, presenting different distributions and size.

\section{LABORATORY TESTS}

\section{A. Concrete specimens}

Three $0.16 \times 0.15 \times 0.6 \mathrm{~m}$ concrete samples were built representing beams. At each beam, between 2 and 3 incisions were cut, and various holes were also drilled (see Figure 1). Table 1 summarizes the three samples tested in the laboratory. Each concrete beam presented a configuration of different cracks width and depth. At each beam, four cases were tested, filling the cuts and holes with different materials (unfilled-air, sand, water and saturated sand). The different cases represent the possible crack conditions in real beams or rigid pavements.

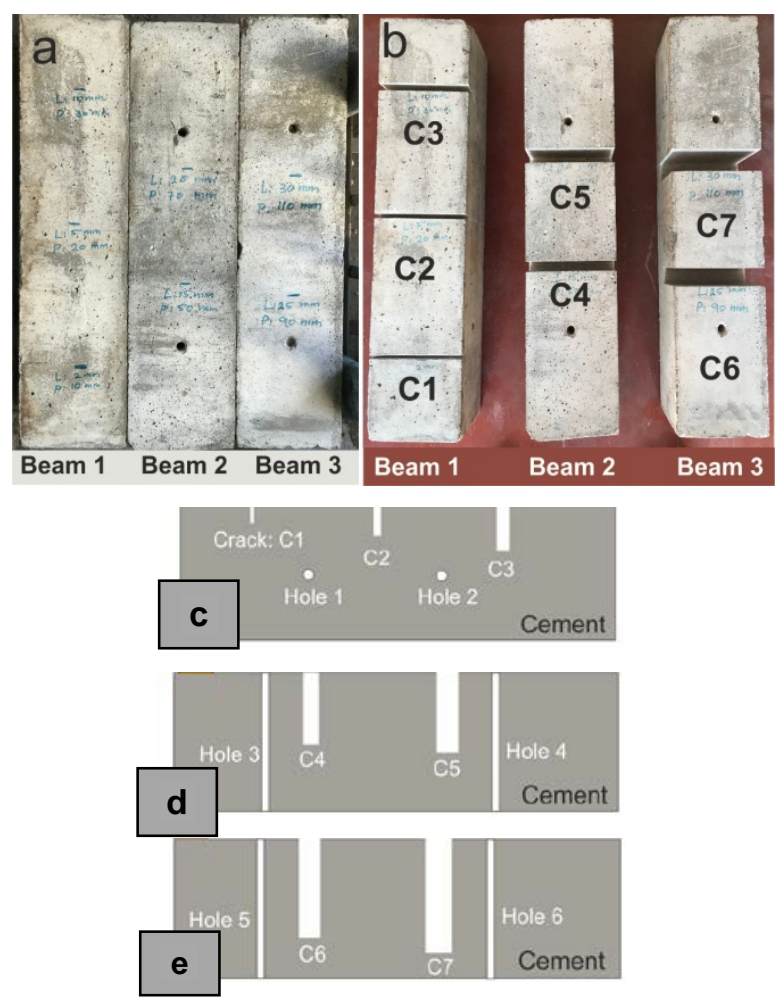

Fig. 1. Concrete beams. a) Beams without incisions. b) Position of holes and incisions. c, d, e) Cross sections of beams 1, 2 and 3.

TABLE I. CHARACTERISTICS OF CUTS AND HOLES

\begin{tabular}{|c|c|c|c|c|c|}
\hline \multirow{2}{*}{ Beam } & \multicolumn{2}{|c|}{ Target } & \multicolumn{2}{|c|}{ Dimension (mm) } & \multirow{2}{*}{$\begin{array}{l}\text { Depth } \\
(\mathrm{mm})\end{array}$} \\
\hline & Cut & Hole & Width & radius & \\
\hline \multirow{5}{*}{1} & $\mathrm{C} 1$ & & 2 & & 10 \\
\hline & $\mathrm{C} 2$ & & 5 & & 20 \\
\hline & C3 & & 10 & & 30 \\
\hline & & $\mathrm{H} 1$ & & 7.5 & 150 \\
\hline & & $\mathrm{H} 2$ & & 7.5 & 150 \\
\hline \multirow{4}{*}{2} & $\mathrm{C} 4$ & & 15 & & 50 \\
\hline & $\mathrm{C5}$ & & 20 & & 70 \\
\hline & & H3 & & 7.5 & 150 \\
\hline & & $\mathrm{H} 4$ & & 7.5 & 150 \\
\hline \multirow{4}{*}{3} & C6 & & 25 & & 90 \\
\hline & C7 & & 30 & & 110 \\
\hline & & $\mathrm{H} 1$ & & 7.5 & 150 \\
\hline & & $\mathrm{H} 2$ & & 7.5 & 150 \\
\hline
\end{tabular}




\section{B. Radar data acquisition}

Radar data was acquired in a radar line along the axis of the beam, with a $2.3 \mathrm{GHz}$ nominal centre frequency antenna, with a trace sampling interval of $2 \mathrm{~mm}$ and a time window of $7 \mathrm{~ns}$. Sampling frequency was $20 \mathrm{GHz}$ (approximately ten times the central frequency).

B-scans were obtained using two different antenna positions with respect the radar line: with the antenna dipoles perpendicular to the radar line (parallel crack orientation), and withthe antenna dipoles parallel to the radar line (antenna rotated $90^{\circ}$ ).

Processing data consisted of dewow and background removal.

\section{LABORATORY RESULTS}

Table 2 summarize the different tests, including the position of the antenna with respect the radar line and the material inside the crack.

TABLE II. DESCRIPTION OF THE GPR MEASUREMENTS

\begin{tabular}{|c|c|c|c|c|}
\hline \multirow{2}{*}{$\begin{array}{c}\text { Filling } \\
\text { Materials }\end{array}$} & \multirow{2}{*}{$\begin{array}{c}\text { Dipole } \\
\text { Orientation }\end{array}$} & \multicolumn{3}{|c|}{ Specimens } \\
\hline & & Beam 1 & Beam 2 & Beam 3 \\
\hline \multirow{2}{*}{ Air } & $\mathbf{X} \mathbf{X} \underset{\text { Line }}{\stackrel{\text { Radar }}{-}-\mathbf{D}}$ & X1 & Y1 & $\mathrm{Z1}$ \\
\hline & $\begin{array}{l}\text { Radar } \\
\text { Line }\end{array}$ & $\mathrm{X} 2$ & Y2 & $\mathrm{Z2}$ \\
\hline \multirow{2}{*}{ Sand } & $\mathbf{X \mathbf { X }} \underset{\text { Line }}{\stackrel{\text { Radar }}{-} \rightarrow}$ & X3 & Y3 & Z3 \\
\hline & $\underset{\text { Line }}{\stackrel{\text { Radar }}{-}-\rightarrow}$ & $X 4$ & Y4 & Z4 \\
\hline \multirow{2}{*}{ Water } & $\mathbf{X X}-\underset{\text { Line }}{\stackrel{\text { Radar }}{-}-\boldsymbol{\rangle}}$ & $\times 5$ & Y5 & Z5 \\
\hline & $\begin{array}{l}\text { Radar } \\
\text { Line }\end{array}$ & A6 & Y6 & Z6 \\
\hline \multirow{2}{*}{$\begin{array}{c}\text { Saturated } \\
\text { Sand }\end{array}$} & $\mathbf{X} \mathbf{X} \underset{\text { Line }}{\stackrel{\text { Radar }}{-} \rightarrow}$ & $X 7$ & Y7 & Z7 \\
\hline & $\begin{array}{l}\text { Radar } \\
\text { Line }\end{array}$ & $\mathrm{X} 8$ & Y8 & Z8 \\
\hline
\end{tabular}

A. Specimen: beam 1

Figure 2 shows the results obtained in the radar analysis of beam 1. In case of the thinner unfilled cracks $(2 \mathrm{~mm})$, the hyperbola detected compared to the same crack but filled with sand, the lighter hyperbola is noticed. The filled cracks with water and saturated sand, the vertical depth of the crack is probably detected with both cases the dipoles perpendicular and parallel to the radar lines, but in the case of the antenna dipoles perpendicular to the radar line results presents stronger hyperbolas.

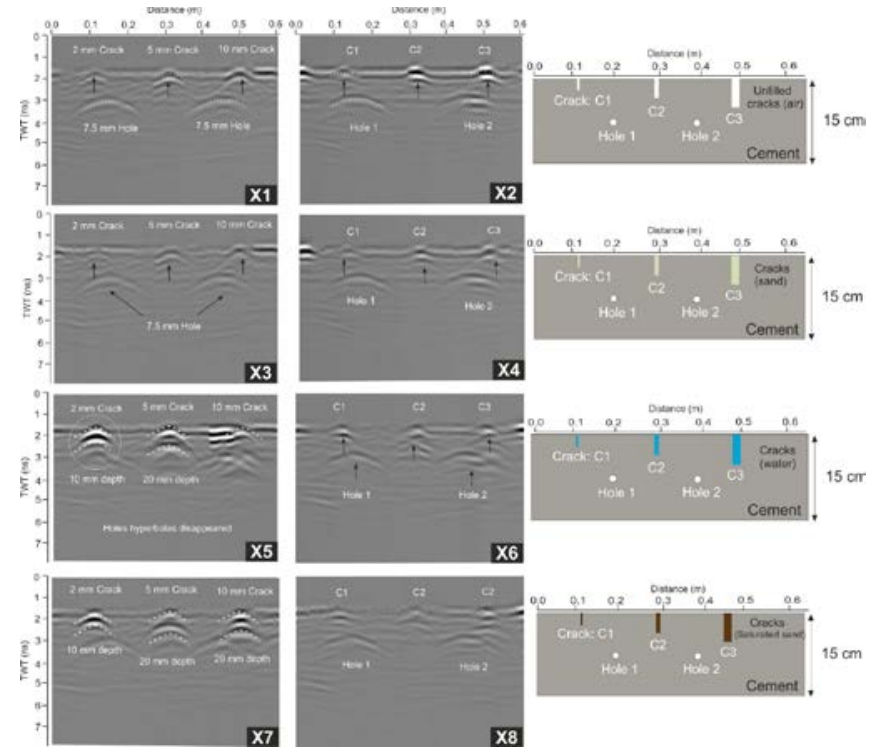

Fig. 2. Results obtained in the concrete beam 1 for the different type of measurements.

Two other unfilled holes (Hole 2 and Hole 2) with radius $(7.5 \mathrm{~mm})$ horizontally drilled in the bottom part of the concrete beam, the effects of both holes clearly detected as hyperbola when other cracks (C1, C2 and C3) remains unfilled cracks and filled with only sand. Both holes disappeared, when other cracks (C1, C2 and C3) filled with water and saturated sand due to the effect of the water content increases the frequency and decrease the wave velocity to penetrate deeper in the concrete beam, very light hyperbola on the top of the hole is detected. Other cracks (5 and $10 \mathrm{~mm}$ ) were detected as a clear hyperbola and the vertical depth of the crack is detected, only in cases of filled with water and saturated sand (in both cases perpendicular and parallel to the radar line).

\section{B. Specimen: beam 2}

All the targets in beam 2 were detected in all cases (Figure 3 ). The existence of water or saturated sand allow to detect the depth of the cracks due to increasing of dielectric constant, the frequency increases and differentiate the crack damage from other parts of the concrete beam, this is only in case of the shallow surface cracks.

\section{Specimen: beam 3}

This concrete beam has two cracks are straight in the vertical depth. The cracks width and depth (C6:25x90 mm and C7:30x110 mm), respectively. In the B-scan that was antenna perpendicular to the radar lines, the width clearly detected in all cases. In the radar images which is antenna parallel to the radar lines, stronger hyperbola was detected. In the case of the crack filled with water, the depth of the lightly detected due to the low wave velocity that could not penetrate the entire depth. In case of the cracks filled with the saturated sand, a hyperbola detected in time window (5ns for the crack depth $90 \mathrm{~mm}$ ), and time window (6.2 for the crack depth $110 \mathrm{~mm}$ ). results show that the orientation of the antenna parallel to the radar line has significant changes to detect the anomalies (Figure 4). 


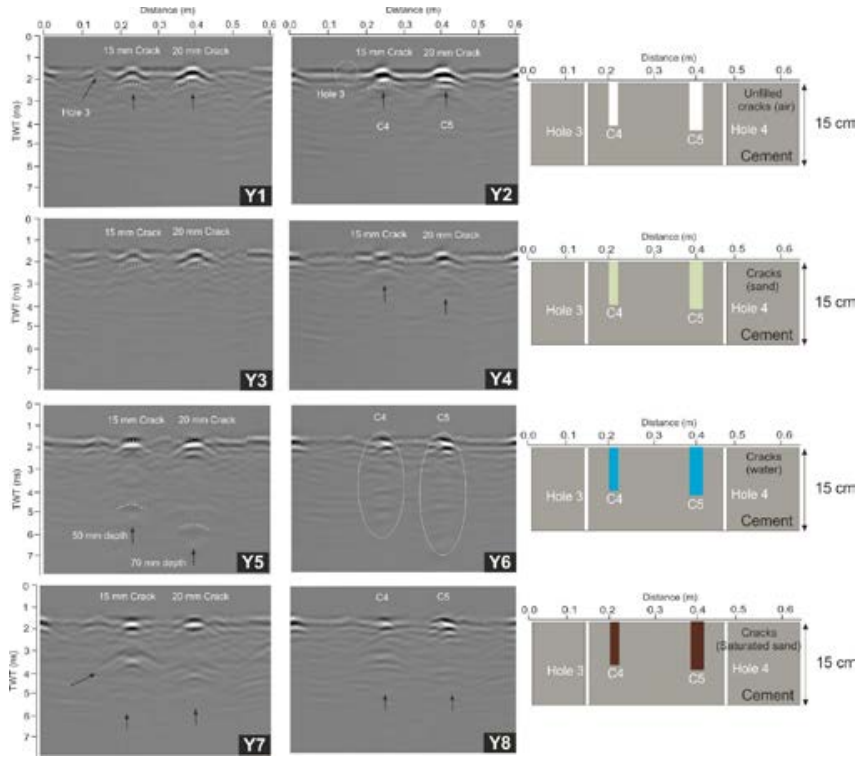

Fig. 3. Results obtained in the concrete beam 2 for the different type of measurements.

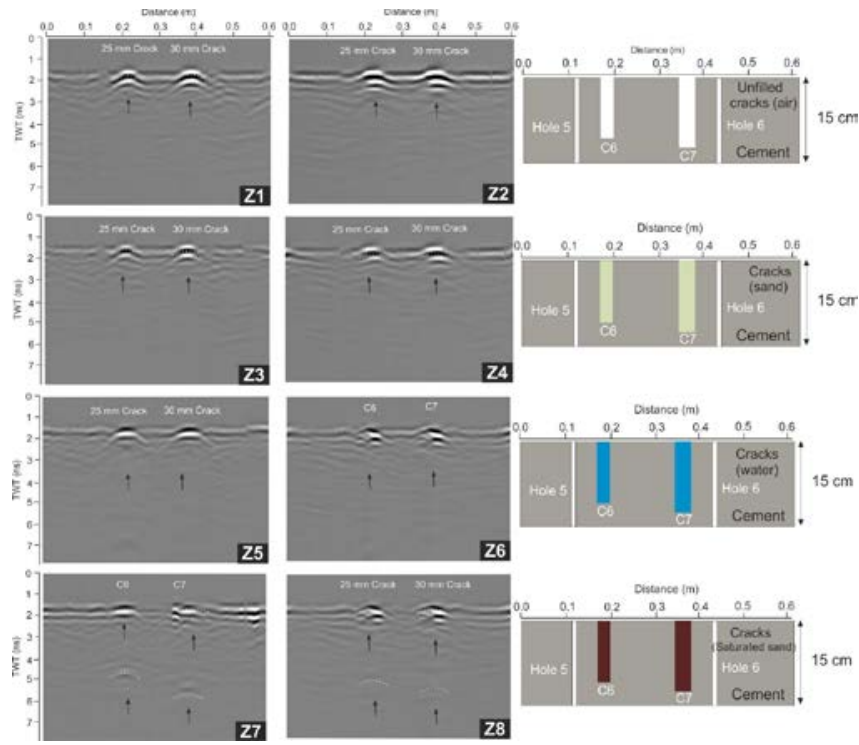

Fig. 4. Results obtained in the concrete beam 3 for the different type of measurements.

\section{COMPUTATIONAL MODELS}

Modelling is a very useful method to help in the GPR data interpretation. Results from computational models are also useful for checking the analysis of the concrete slab with various crack widths. GPR simulation is commonly carried out using numerical modelling finite-difference time-domain (FDTD) method [5, 6]. In this case study, a 2D numerical simulation was carried out by using GprMax2D, which is a very popular FDTD simulation software [7]. The 2D models represent the experimental works carried out in the laboratory with no relevant error considered. A similar approach was used previously [8]. Several models were prepared by using a small grid size cell $(1 \mathrm{~mm} \times 1 \mathrm{~mm})$ to simulate the smallest object in the simulation (e.g. $2 \mathrm{~mm}$ crack width). The cement concrete slab $(0.75 \mathrm{~m} \times 0.15 \mathrm{~m})$ placed and overlaid with the asphalt pavement layer $(0.75 \mathrm{~m}$ $\times 0.07 \mathrm{~m}$ ) and $0.1 \mathrm{~m}$ for the coupling interface between the GPR and the ground surface of the asphalt layer as shown in Figure 1. The same central frequency of the laboratory experiments was used in the simulation, which was 1600 $\mathrm{MHz}$, and the signal considered as a ricker wavelet [9]. The separation between the receiver and the transmitter was 60 $\mathrm{mm}$, per indication from the manufacturer, and the initial starting position of the antenna was $20 \mathrm{~mm}$, or 20 cells. The time window was the same as used in laboratory experiments.

Finally, it must be noted that all the interface between antenna and materials were assumed to be flat. However, the real interfaces were not smooth. This effect resulted in an overall homogeneity of the modelling [9]. The electrical properties of the simulated materials (e.g. permeability, permittivity and conductivity) are important factors that affect the propagation (transmission, reflexion, attenuation, etc.) electromagnetic waves $[9,10]$. The dielectric constant of the cement concrete slab was estimated by calculating the propagation speed of the emitted wave through one of the concrete beams used for experimental works, which resulted in a dielectric of 5.5. The dielectric of the asphalt was considered 4. Both concrete and asphalt were considered as dry and nonmagnetic materials by considering $0.005 \mathrm{~S} / \mathrm{m}$ for conductivity, zero for electric conductivity and relative permeability.

Figures 5, 6 and 7 present the different measurements in the three samples. The differences produces by the materials inside the holes and cracks are more visible than in the case of the laboratory tests.
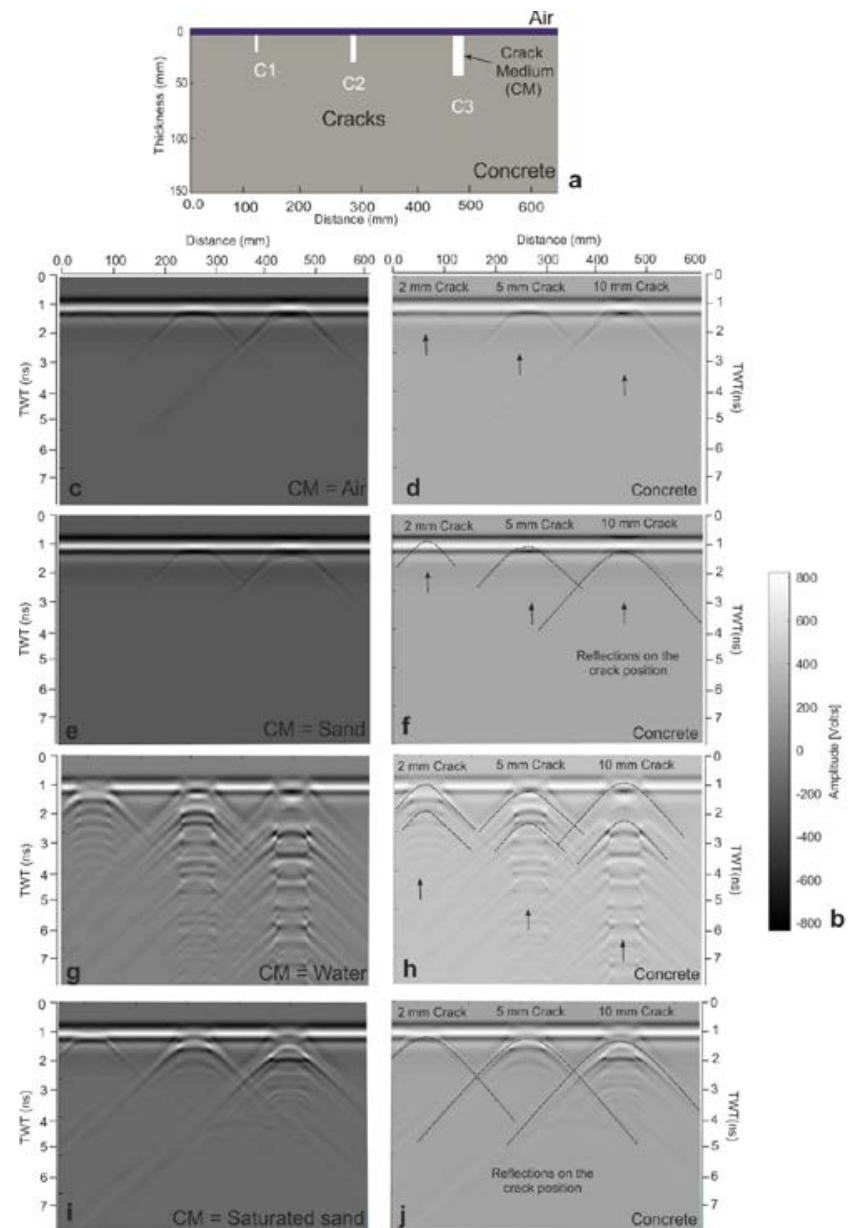

Fig. 5. Simulation of the different cases in beam 1. 

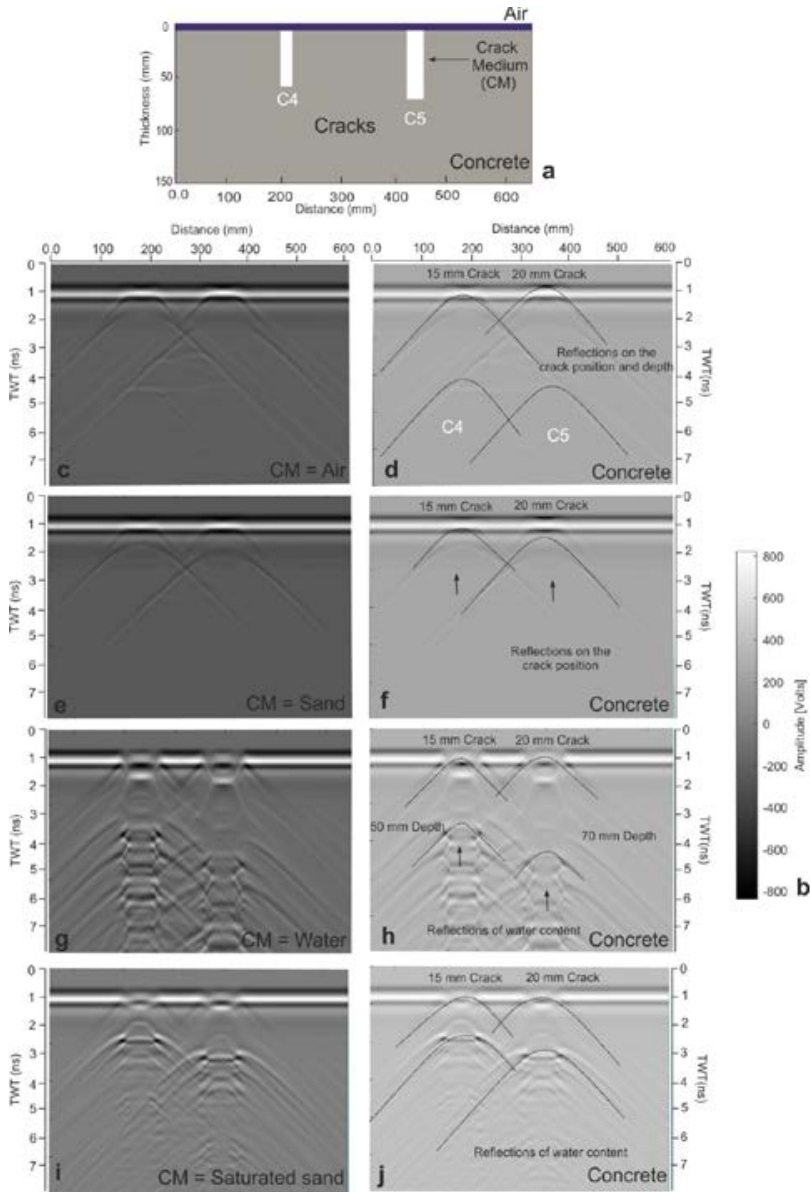

Fig. 6. Simulation of the different cases in beam 2 .
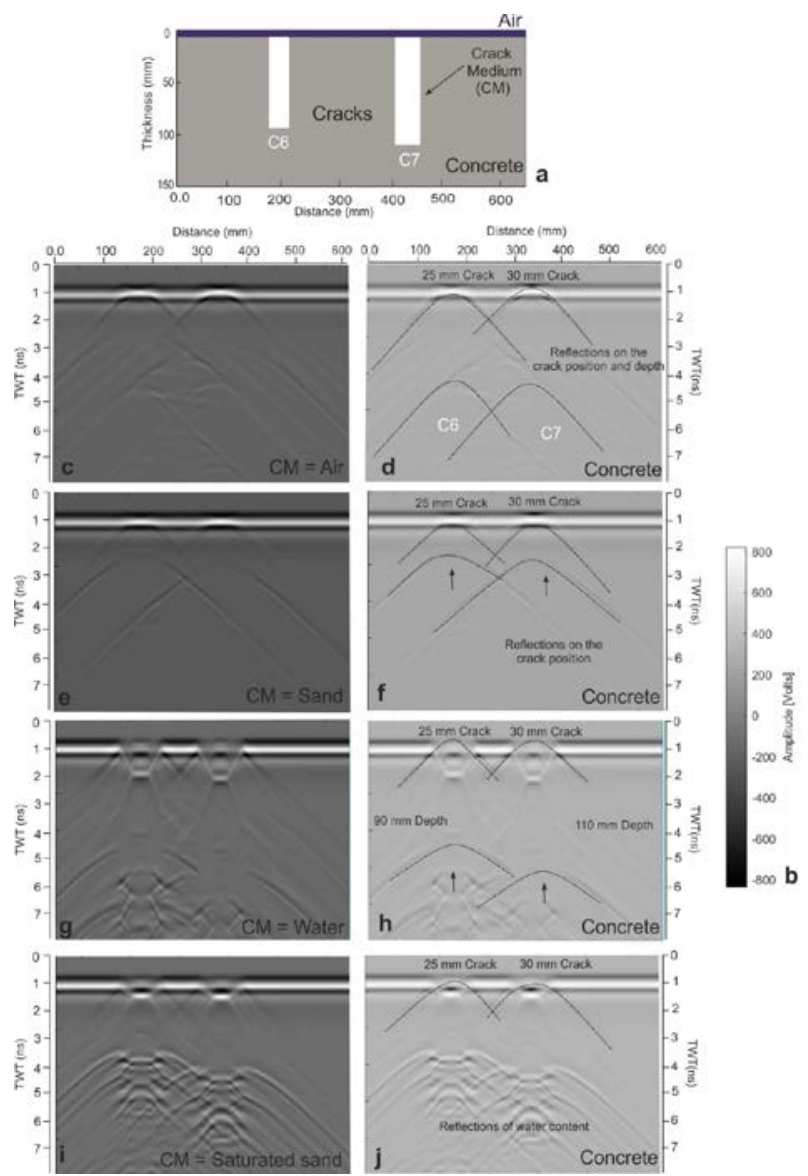

Fig. 7. Simulation of the different cases in beam 3 .
The different crack widths were simulated and modelled to investigate and compare with the laboratory results. The crack widths in the concrete slab were created along the 15 $\mathrm{cm}$ depth of the cement concrete slab. In the simulated radargram, the crack generates the characteristic hyperbolic signal in the top of the crack. The amplitude of the hyperbola increased by increasing the width of the, showing very similar results with the laboratory experiments obtained previously. On the other hand, the amplitude corresponding the $2 \mathrm{~mm}$ crack is very small when compared with the (15 or $30 \mathrm{~mm}$ ) crack width.

\section{FIELD SURVEY: RIGID PAVEMENT ASSESSMENT}

A survey in a rigid pavement road was carried out to compare results with the laboratory tests and computational models. The purpose of this intensive investigation to explore the ability of the GPR in detection of cracks filled with different materials due to the climate conditions. The field case study was the rigid pavement in the highway (Lisbon-A) at the station $(52+900$ and $53+000)$. The road structure of the pavement was $(20 \mathrm{~cm}) \mathrm{BRC}$ concrete and $(15$ $\mathrm{cm}$ ) lean concrete on the surface layer. Two sections selected to evaluate the cracks (Figure 8).

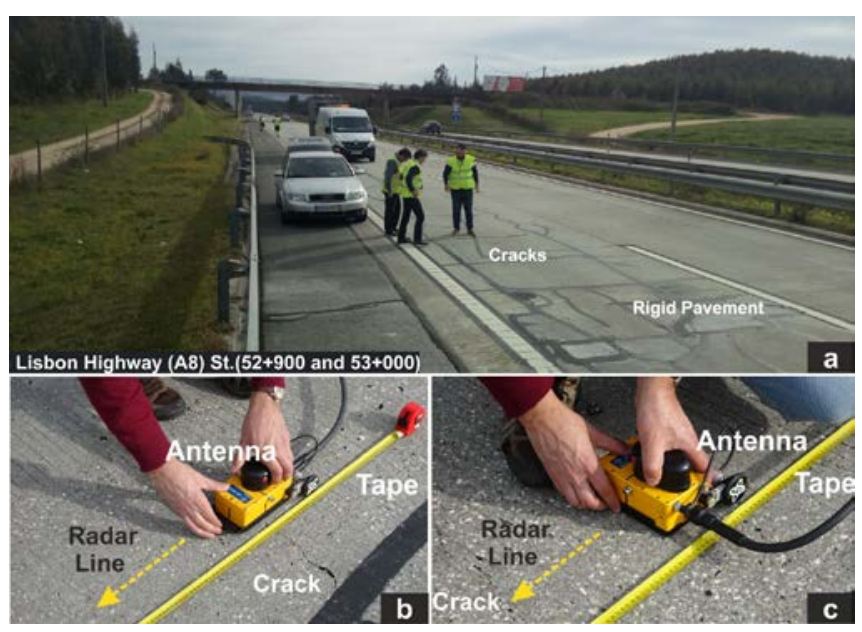

Fig. 8. Radar data acquisition. a) View of the site. b) Radar data acquisition with the antenna dipoles perpendicular to the radar line (parallel to the crack). c) Radar data acquisition with the antenna dipoles parallel to the radar line (perpendicular to the crack).

2.3 GHz central frequency antenna was used to evaluate the cracks in the rigid pavement survey. GPR data acquired in two orientation for each section; antenna perpendicular to the radar line (parallel to the crack) and the antenna parallel to the radar line (perpendicular to the cracks).

\section{A. Rigid pavement assessment results}

The rigid pavement was investigated with GPR, radargrams were processed by dewow and background removal filters. Results related with ground survey on the concrete in the rigid pavement show the existence of some cracks in the surface of the pavement and probably one early cracking (growth crack) is detected. The structure of pavement is not homogeneous, changes of the road structure (layers) are detected in this study. For section (st.52+900), the first case which is antenna dipoles perpendicular to the radar line (parallel to the cracks), the structure of the road pavement is clearly detected as a series of hyperbolas which is corresponding the BRC layer and the lean concrete layer is detected. Two cracks on the surface are detected as surface cracks, and one important change below the surface of the 
concrete also detected as early cracks which growing to release to the surface (Figure 9). The survey was repeated with the antenna parallel to the radar line (Figure 10). In case of the antenna dipoles parallel to the radar lines (perpendicular to the cracks). Results shows the stronger hyperbolas of the cracks, and the difference in layers of road structure.

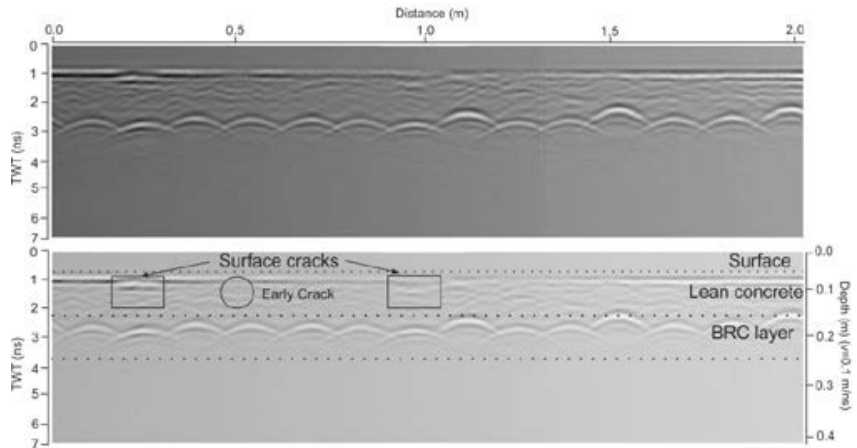

Fig. 9. Radar data acquired with $2.3 \mathrm{GHz}$ centre frequency antenna perpendicular to the radar line on the rigid pavement (St.52+900).

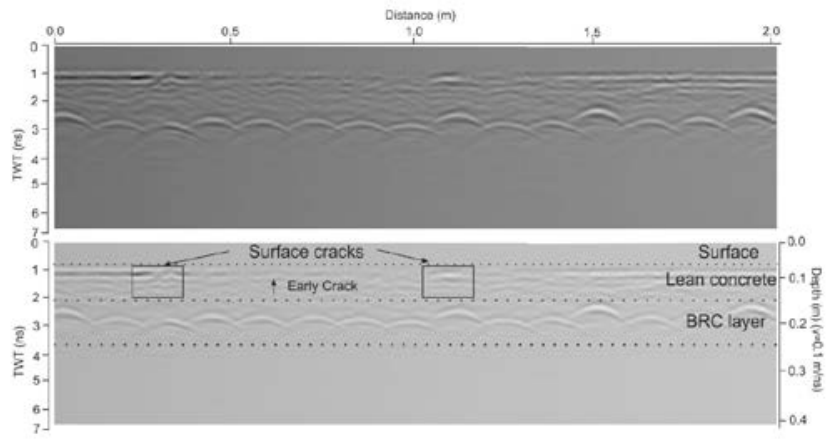

Fig. 10. Radar data acquired with $2.3 \mathrm{GHz}$ centre frequency antenna Parallel to the radar line on the rigid pavement (St.52+900).

Figure 11 presents the section that correspond to the (st.53+000). Results of the radar images shows that three cracks were detected $(0.40,095$ and 1.70 meters), respectively. However, the geological discontinuity is detected in time window (2.2 ns), corresponding to the contact between road layers.

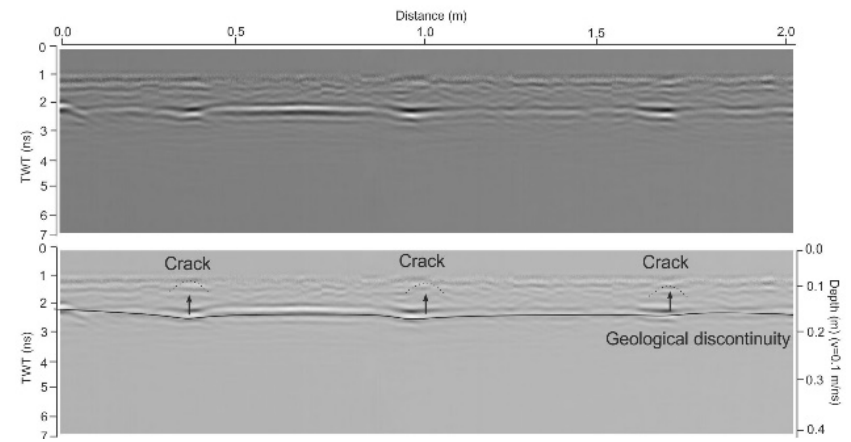

Fig. 11. Radar data acquired with $2.3 \mathrm{GHz}$ centre frequency antenna perpendicular to the radar line on the rigid pavement (St. 53+000). The position of the the antenna dipoles were perpendicular to the radar line (parallel to the cracks).
Radar image was taken from the configuration of the antenna dipoles parallel to the radar line (perpendicular to the cracks), probably shows the clearer hyperbola in the crack positions (Figure 12).

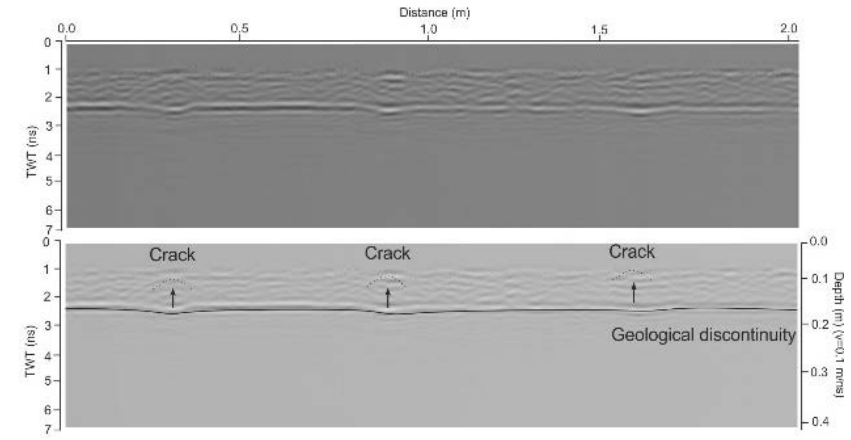

Fig. 12. Radar data acquired with $2.3 \mathrm{GHz}$ centre frequency antenna Parallel to the radar line on the rigid pavement (St. $53+000)$

\section{DISCUSSION AND CONCLUSIONS}

In this case study, a commercial Ground Penetrating Radar (GPR) system, RAMAC/GPR, equipped with a 1.6 $\mathrm{GHz}$ high-resolution frequency antenna was used as a nondestructive method to determine the capability of GPR to identify cracking occurrence and width in cement concrete slabs placed below bituminous road pavements. Various crack widths were selected (e.g. 2, 5, 10, 15, 20, 25 and 30 $\mathrm{mm})$. Two different ways to acquire data were carried (dragging the antenna perpendicularly to the crack but with the antenna axis oriented, firstly, perpendicularly and, secondly, parallel to the crack). For processing the radargrams, the continuous background signal had to be removed to enhance the diffraction hyperbolas from the crack. Generally, all cracks were detected regardless of orientation and width, with the exception of the thinnest one (2 mm). The way the crack was detected is via the occurrence of a hyperbola at the top of the crack. Additionally, the parallel phase readings allowed the detection of the crack in depth (for a width superior to 15 $\mathrm{mm}$ ) and produced higher amplitude hyperbolae, which could indicate a more probable detection of cracks.

Numerical simulation has been carried out to assess experimental results. Due to software limitations (2D), only perpendicular readings were simulated. Results confirm the increase of the crack width with a higher amplitude hyperbola, showing a very similar trend relatively to experimental results.

The main findings of the results;

- Parallel readings produce more energetic reflections than normal readings.

- The increase in width is accompanied in all cases by an increase in amplitude.

- For larger cracks, the difference is softened because it is turning as a layer, and thus, the discontinuity of the crack disappears.

- The amplitude in the simulated radargrams is greater than the perpendicular phase produced by laboratory experiments. 


\section{ACKNOWLEDGMENT (Heading 5)}

This research has been partially funded by the Spanish Ministry of Economy and Competitiveness (MINECO) of the Spanish Government and by the European Regional Development Fund (FEDER) of the European Union (UE) through projects referenced as CGL2011-23621 and CGL2015-65913 -P (MINECO / FEDER, UE). The research is also a contribution to the EU funded COST Action CA15202 (SARCOS), "Self-healing as prevention Repair of Concrete Structures" We appreciate the support of Duhok Polytechnic University, University of Minho and Universitat Politècnica de Catalunya.

\section{REFERENCES}

For papers published in translation journals, please give the English citation first, followed by the original foreignlanguage citation [6].

[1] S.I.R. Amorim, J.C. Pais, A.C. Vale, M.J.C. Minhoto. (2015). A model for equivalent axle load factors, Int. J. Pavement Eng. 16 (01) 881-893.
[2] Y.H. Huang, (1993). Pavement analysis and design, Prentice Hall, Englewood, Cliffs, N.J., USA.

[3] J.C. Pais, S.I.R. Amorim, M.J.C. Minhoto. (2013). Impact of traffic overloads on road pavements performance, ASCE J. Transp. Eng. 139 (9) 873-879.

[4] A. Taflove, (1995). Computational Electrodynamics: The FiniteDifference Time- Domain Method. Artech House.

[5] [6] K.S. Yee. (1966). Numerical solution of initial boundary value problems involving Maxwell's equations in isotropic media, IEEE Trans. Antennas Propag. 14 302-307.

[6] [7] A. Giannopoulos. (2005). Modelling ground penetrating radar by GprMax, Construction and Building Materials 19 (10) 755-762, http://dx.doi. org/10.1016/j.conbuildmat.2005.06.007.

[7] [8] F. M. Fernandes and J. C. Pais. (2017). "Laboratory observation of cracks in road pavements with GPR,” Constr. Build. Mater., vol. 154, pp. 1130-1138.

[8] [9] D.J. Daniels, (2004). Ground Penetrating Radar - 2nd Edition. Radar, sonar, navigation and avionics series 15, IEE, London, UK.

[9] [10] A. Porubiaková, J. Komaèka. (2015). A comparison of dielectric constants of various asphalts calculated from time intervals and amplitudes, Procedia Eng. 111 660-665. 